\title{
Soft tissue response to mandibular advancement using 3D CBCT scanning
}

\author{
Rhita C. Almeida, Lucia H.S. Cevidanes, Felipe A.R. Carvalho, Alexandre T. Motta, Marco \\ A.O. Almeida, Martin Styner, Timothy Turvey, William R. Proffit, and Ceib Phillips \\ Department of Orthodontics, School of Dentistry, University of North Carolina at Chapel Hill, USA
}

\begin{abstract}
This prospective longitudinal study assessed the 3D soft tissue changes following mandibular advancement surgery. Cranial base registration was performed for superimposition of virtual models built from cone beam computed tomography (CBCT) volumes. Displacements at the soft and hard tissue chin $(n=20)$, lower incisors and lower lip $(n=21)$ were computed for presurgery to splint removal (4-6 week surgical outcome), presurgery to 1 year postsurgery (1-year surgical outcome), and splint removal to 1 year postsurgery (postsurgical adaptation). Qualitative evaluations of color maps illustrated the surgical changes and postsurgical adaptations, but only the lower lip showed statistically significant postsurgical adaptations. Soft and hard tissue chin changes were significantly correlated for each of the intervals evaluated: presurgery to splint removal $(\mathrm{r}=0.92)$, presurgery to 1 year postsurgery $(\mathrm{r}=0.86)$, and splint removal to 1 year postsurgery $(\mathrm{r}=0.77)$. A statistically significant correlation between lower incisor and lower lip was found only between presurgery and 1 year postsurgery ( $\mathrm{r}=0.55)$. At 1 year after surgery, $31 \%$ of the lower lip changes were explained by changes in the lower incisor position while $73 \%$ of the soft tissue chin changes were explained by the hard chin. This study suggests that $3 \mathrm{D}$ soft tissue response to mandibular advancement surgery is markedly variable.
\end{abstract}

\section{Keywords}

soft tissue changes; mandibular advancement surgery; 3D analysis

For the surgeon, the ability to plan accurate skeletal movements to correct a mandibular deficiency is critical. Clinicians have assumed that the soft tissue must adapt and follow the hard tissue movements, but even after decades of study, the association between the skeletal and soft tissue movements following mandibular advancement is not well defined. Previous studies have reported that the soft tissue chin tended to follow the movement of the hard tissue chin closely but that the lower lip position was much more difficult to predict. ${ }^{13}, 18$

(C) 2010 International Association of Oral and Maxillofacial Surgeons. Published by Elsevier Ltd. All rights reserved.

Corresponding Author: Dr. Lucia H.S. Cevidanes Assistant Professor Department of Orthodontics UNC School of Dentistry Chapel Hill, NC 27599-7450, USA cevidanl@ dentistry.unc.edu Telephone (919) 357-8603 Fax (919) 843-8864.

DECLARATIONS Competing interests: None declared

Ethical approval: The work has been approved by the University's IRB Office, Study \#03-1642. Subjects gave informed consent to participate in the study.

Publisher's Disclaimer: This is a PDF file of an unedited manuscript that has been accepted for publication. As a service to our customers we are providing this early version of the manuscript. The manuscript will undergo copyediting, typesetting, and review of the resulting proof before it is published in its final citable form. Please note that during the production process errors may be discovered which could affect the content, and all legal disclaimers that apply to the journal pertain. 
Assessments of soft tissue changes during and after surgery require three dimensional (3D) analysis and superimposition due to the complexity of the behavior of the soft tissue and the inability to measure asymmetries in two dimensional (2D) images. Technologies such as 3D photogrammetry $2,3,8,19,24$ and laser scanning ${ }^{11,12,17,21}$ of the face have been used for 3D soft tissue superimposition, but their major limitation has been the inability to standardize registration of the images over time. Current procedures to integrate 3D facial images have reported significant errors in head positioning, ${ }^{11,} 12$ and potential errors in facial expression have not been assessed. ${ }^{6}$

This study assessed the stability of 3D soft tissue changes following mandibular advancement, and evaluated the association between soft and hard tissue changes using registration on the cranial base for the superimposition of 3D virtual models built from cone beam computed tomography (CBCT) volumes.

\section{Patients and Methods}

25 patients ( 7 men, 18 women; mean age $30.8 \pm 13.08$ years) scheduled for mandibular advancement surgery were recruited for this prospective observational study. The protocol was approved by the Biomedical Institutional Review Board, and informed consent was obtained from all subjects. All patients had skeletal Class II discrepancies with $>5 \mathrm{~mm}$ overjet that was severe enough to warrant orthognathic surgery. All patients had pre- and post-surgical orthodontic treatment and had mandibular advancement surgery with bilateral sagittal split osteotomy. 9 participants also had genioplasty as an adjunctive procedure. Patients with anterior open bite, cleft lip or palate, or skeletal disharmonies from trauma or degenerative conditions such as rheumatoid arthritis were excluded.

CBCT scans were taken before surgery, at splint removal (4-6 weeks postsurgery), and 1 year postsurgery (after orthodontic treatment) with the NewTom 3G (AFP Imaging, Elmsford, NY, USA). The imaging protocol involved a $36 \mathrm{~s}$ head CBCT scan with a 12 in field of view. All CT scans were acquired with the patient biting on a thin wax bite to maintain centric occlusion. ${ }^{25}$ In 5 cases, the CBCT imaging field of view did not include all soft tissue structures, resulting in data for 21 patients for the lower lip and 20 patients for the soft tissue chin (mandibular advancement alone $\mathrm{n}=11$; and mandibular advancement and genioplasty $n=9$ ). The $3 \mathrm{D}$ models were constructed from CBCT images with a voxel dimension of $0.5 \times 0.5 \times 0.5 \mathrm{~mm}$. Image segmentation of the anatomic structures of interest and the 3D graphic rendering were done using ITK-SNAP (open-source software, www.itksnap.org). ${ }^{26}$

The presurgery and postsurgery images were registered using the cranial base as a reference, since this structure is not altered by surgery. ${ }^{16} \mathrm{~A}$ fully automated voxel-wise rigid registration method was performed with IMAGINE (open-source software,

http://www.ia.unc.edu/dev/download/imagine/index.htm). The software compares 2 images by using the intensity gray scale for each voxel of the presurgical cranial base. Registration of the images was based on the cranial base surface. Soft tissue structures are not stable enough for accurate registration. Virtual models of the soft and hard tissue were relocated with the cranial base (Figure 1).

After the registration step, all reoriented virtual models, originally saved in .gipl format, were converted to an open inventor format (.iv) by Vol2Surf (publicly available software). This allowed quantitative evaluation of the greatest surface displacement by the CMF application software (developed at the M.E. Müller Institute for Surgical Technology and Biomechanics, University of Bern, Switzerland, under the funding of the Co-Me network, http://co-me.ch).5 The CMF tool calculates thousands of color-coded point-to-point 
comparisons (surface distances in $\mathrm{mm}$ ) between the 3D models, so that the difference between 2 surfaces at any location can be quantified. ${ }^{7}$ For quantitative assessment of the changes between the 3D surface models, the isoline tool was used. It allows the user to define a surface-distance value that is expressed as a contour line (isoline) that corresponds to regions having a surface distance equal to or greater than the defined value. The isoline tool was used to quantitatively measure the greatest displacements between points in the 3D surface models for the lower incisor edges, hard chin, soft chin and lower lip (Figures 2 and 3 ). Positive values indicated anterior-inferior displacement and negative values posteriorsuperior displacement.

For the right lower incisor, the maximum surface distance was measured at the incisor's border, so that the presence of brackets at splint removal would not interfere with the measurements. The hard tissue chin region included the surface from the chin prominence to the distal surface of the lower canines (Figure 2A). The soft tissue chin region was defined as the area under the lower lip between the lip commissures. The lower lip region was defined as the lip vermilion (Figure 2B).

The largest displacements at each anatomic region of interest were computed for presurgery to splint removal (4-6 week surgical outcome), presurgery to 1 year postsurgery (1 year surgical outcome), and splint removal to 1 year postsurgery (postsurgical adaptation).

The greatest displacement for each region of 10 randomly selected superimpositions was measured twice, at a 2 week interval. Agreement between the displacements of the replicates was assessed by using intraclass correlations (ICC). Paired t-tests were used to assess if the average change from splint removal to 1 year postsurgery as well as the average difference in hard and soft tissue displacement for each time interval was zero. Pearson correlation coefficients were used to assess the association between the soft and hard chin as well as lower incisors and lower lip changes. Level of significance was set at 0.05 . The percent of patients for whom the difference in the hard and soft tissue displacement was greater than $2 \mathrm{~mm}$ was calculated and displayed graphically.

\section{Results}

Agreement between the replicated measurements was excellent $(\mathrm{P}<0.001)$ for all anatomic regions: hard chin (ICC=0.98); lower incisor (ICC=0.94); soft chin (ICC=0.98); lower lip (ICC=0.96).

Soft tissue facial results varied regardless of whether they had genioplasty. Some swelling was still present at splint removal, even in cases with mandibular advancement only and no genioplasty. Soft tissue facial results in the 1 year follow up improved for some patients (Figure 4), partial relapse was observed in some (Figure 5) and most remained stable (Figure $6)$.

Color maps of the mandibular changes allowed clear visual analysis of the anterior-inferior displacement of the hard chin at splint removal as an outcome of surgery. The color maps also revealed a tendency for slight superior-posterior adaptation of the hard chin in the postsplint removal period. The qualitative evaluation of the soft tissue chin showed that this region had the same behavior as the hard tissue chin at all time points, but changes in soft tissue were in general slightly more marked than skeletal changes.

Color map observation indicated that dental changes were less marked than skeletal changes. The lower incisor edges were also displaced anterior-inferiorly as a result of the mandibular advancement surgery, with slight postsurgical adaptation in the opposite direction. The lower lip anterior-inferior movement at splint removal was greater than the lower incisor 
movement, and the postsurgical posterior-superior adaptation was also more marked than the lower incisor changes.

The average difference in the change from presurgery to splint removal compared with the change from splint removal to 1 year postsurgery was only statistically significantly different from zero for the inferior lip displacements $(\mathrm{P}=0.01)$.

The correlation between the soft and hard tissue chin displacements were statistically significant $(\mathrm{P}<0.0001)$ for presurgery to splint removal $(\mathrm{r}=0.92)$, splint removal to 1 year postsurgery $(r=0.77)$ and presurgery to 1 year postsurgery $(r=0.86)$ (Table 1$)$. The average displacement of the soft tissue chin was greater than that of the hard tissue chin for all three time intervals, but the average difference between the hard and soft tissue displacements from splint removal to 1 year after surgery was not statistically significant $(\mathrm{P}=0.98$, Table 2$)$.

For $10 \%$ of the subjects, the soft tissue chin changes between presurgery and splint removal in an anterior inferior direction were more than $2 \mathrm{~mm}$ larger than the hard tissue chin changes. Between splint removal and 1 year, a slightly higher percentage $(15 \%)$ of the subjects had a soft tissue displacement that exceeded the hard tissue displacement by $2 \mathrm{~mm}$ or more, while $15 \%$ had soft tissue changes that were more than $2 \mathrm{~mm}$ smaller than the hard tissue change (Figure 7). The chin displacement from presurgery to 1 year postsurgery explained $73 \%$ of the variability in the soft tissue chin changes, which is less than the $85 \%$ that was observed for presurgery to splint removal (Table 1). The correlation between the displacement of the lower incisor and the lower lip was statistically significant for changes between presurgery and 1 year postsurgery $(r=0.55)$, which means that only $30 \%$ of the variability of the lower lip displacement was explained by changes in the lower incisor position (Table 1). The average difference between the lower incisor and lower lip displacements was not statistically significant (Table 3).

Between presurgery and splint removal, approximately $20 \%$ of patients showed lower incisor changes more than $2 \mathrm{~mm}$ larger than the inferior lip changes, while more than $30 \%$ had a significant greater displacement of the lip compared with the lower incisor. From splint removal to 1 year postsurgery, approximately $20 \%$ of the patients had more than 2 $\mathrm{mm}$ difference between the amount of lower lip and lower incisor displacements. Between presurgery to 1 year postsurgery over $50 \%$ of the sample had more than $2 \mathrm{~mm}$ difference between the lower lip and lower incisor displacement (Figure 8).

\section{Discussion}

Figure 9 gives examples of the three different periods analyzed. \{AQ1\} CBCT images display the soft-tissue surfaces accurately, but noise in the image can negatively affect the quality of the soft tissue in the CBCT volume (Figure 5). 3D photographs provide additional information about color and surface texture, as well as higher resolution. ${ }^{7}$ No soft tissue structures are stable enough to allow registration between before- and after-treatment images, because the soft tissues change with growth, treatment, head posture, weight gain or loss, aging and facial expression. 3D photographs provide no hard tissue information and an assessment of the associations between soft and hard tissue changes would not be possible. Alternatively, the use of 3D photographs registered to CBCT images could improve soft tissue assessments. Maal et al. ${ }^{14}$ reported $\pm 1.9 \mathrm{~mm}$ registration errors between $3 \mathrm{D}$ photographs and CBCT at the lateral neck, mouth and around the eyes.

An important step toward overcoming these problems would be simultaneous acquisition of $\mathrm{CBCT}$ and 3D photographs, but that is not possible at present. Problems that need to be overcome with 3D photograph superimposition include inadequate use of fiducials, head position in acquisition, soft tissue capture errors, and current use of non-rigid registration 
deformation of soft tissue contours to allow matching of 3D photographs to CBCT soft tissues.

Between presurgery and splint removal, over $10 \%$ of patients had a displacement of more than $2 \mathrm{~mm}$ in the soft tissue chin in relation to the hard tissue chin. This percentage was even higher $(15 \%)$ for the period between splint removal and 1 year postsurgery, but in the same period another $15 \%$ had a smaller soft tissue than hard tissue change. There was a general tendency, supported by the moderately high correlations, for the soft tissue chin change during all intervals to be directionally the same as the hard tissue chin, which agrees with previous studies using lateral cephalometrics. $1,4,9,22$ Several studies using cephalometric examinations have found that the hard chin and the soft chin would have a displacement ratio of $1: 1,9,22,23$ however, ratios should not be used as predictors. Ratios are simplistic mathematical representations of the relation of the anatomic regions of interest displacements that do not reflect the individual variability in response. Individual variability in the response of the soft tissues must be taken into account when simulating and planning the soft tissue surgical outcomes.

The larger displacement, on average, of the lower incisors relative to the lower lip during all time intervals observed in this study must be interpreted with caution. Between presurgery and 1 year postsurgery, almost $40 \%$ of patients in this study had $2 \mathrm{~mm}$ or more of larger displacements of the incisors compared with lower lip changes. This could be explained by four factors: the presence of brackets on the teeth at the pre- and 6 week postsurgery scans, and their absence at 1 year postsurgery when orthodontics had been completed and braces had been removed; some edema and swelling is often still present at splint removal; slight variation in facial expression since it is difficult to reproduce the same facial mimics for all time points; and compensatory movement of the incisors. Simmons et al. ${ }^{20}$ reported that even with postsurgical relapse of $2-4 \mathrm{~mm}$ in the position of the mandible at 5 year recall, the overjet did not change significantly because the incisors moved forward as the mandible moved back. Previous studies using cephalometric radiographs have also indicated that the lip position is not as predictable as the soft tissue chin when compared with the underlying hard tissue changes. Those studies reported ratios between lower incisors and lower lip ranging from $0.26: 1$ to $0.85: 1 .^{13,18}$

For all the time intervals studied, the large standard deviations relative to the mean reflect the individual variability of both hard and soft tissue changes postsurgically. In recent years, a growing number of commercially available programs for 3D virtual surgery and visualization have appeared. The biggest drawback to these programs is the lack of validation of outcomes. Soft tissue predictions lack validation and are difficult to predict accurately in three dimensions. The current commercially available programs utilize spring deformation and morphing programs for soft tissue surgical predictions. This is not biomechanically accurate, nor has it been validated. Validation of soft tissue outcomes would greatly improve patient presentation and understanding of surgical outcomes.

In general, this evaluation using 3D images has supported previous findings from 2D radiographs that the soft chin changes following mandibular advancement are more predictable when compared with the hard tissue chin than the lower lip changes relative to the lower incisor. Further investigation is needed to understand and allow simulation and planning of the actual soft tissue surgical outcomes of the craniofacial components.

\section{Acknowledgments}

Funding: NIH grants DE-017727, DE-018962 and DE-005215 from NIDCR, and grant UL1RR025747 from NCRR 


\section{REFERENCES}

1. Albrechtsen LL, BE. Changes in lower lip cross-sectional area subsequent to mandibular advancement surgery. Int J Adult Orthod Orthognath Surg. 1997; 12:287-296.

2. Aldridge K, Boyadjiev SA, Capone GT, DeLeon VB, Richtsmeier JT. Precision and error of threedimensional phenotypic measures acquired from $3 \mathrm{dMD}$ photogrammetric images. Am J Med Genet A. 2005; 138A:247-253. [PubMed: 16158436]

3. Ayoub AF, Xiao Y, Khambay B, Siebert JP, Hadley D. Towards building a photo-realistic virtual human face for craniomaxillofacial diagnosis and treatment planning. Int J Oral Maxillofac Surg. 2007; 36:423-428. [PubMed: 17428638]

4. Bailey LJ, Collie FM, White RP Jr. Long-term soft tissue changes after orthognathic surgery. Int J Adult Orthodon Orthognath Surg. 1996; 11:7-18. [PubMed: 9046623]

5. Chapuis J, Schramm A, Pappas I, Hallermann W, Schwenzer-Zimmerer K, Langlotz F, Caversaccio M. A new system for computer-aided preoperative planning and intraoperative navigation during corrective jaw surgery. IEEE Trans Inf Technol Biomed. 2007; 11:274-287. [PubMed: 17521077]

6. Curry SBS, Carlson S, Beers A, Boyd R. Integrated three-dimensional craniofacial mapping at the Craniofacial Research Instrumentation Laboratory / University of the Pacific. Semin Orthod. 2001; 7:258-265.

7. Gerig, GJM.; Chakos, M. Valmet: a new validation tool for assessing and improving 3D object segmentation. MICCAI: Proceedings of the International Society and Conference Series on Medical Image Computing and Computer-Assisted Intervention; 2001. p. 516-528.

8. Goos MI, Alberink IB, Ruifrok AC. 2D/3D image (facial) comparison using camera matching. Forensic Sci Int. 2006; 163:10-17. [PubMed: 16337353]

9. Hamada T, Motohashi N, Kawamoto T, Ono T, Kato Y, Kuroda T. Two-dimensional changes in soft tissue profile following surgical mandibular advancement in Japanese retrognathic adults. Int J Adult Orthodon Orthognath Surg. 2001; 16:272-279. [PubMed: 12390005]

10. Hershey HG, Smith LH. Soft-tissue profile change associated with surgical correction of the prognathic mandible. Am J Orthod. 1974; 65:483-502. \{AQ2\}. [PubMed: 4524314]

11. Kau CH, Cronin AJ, Richmond S. A three-dimensional evaluation of postoperative swelling following orthognathic surgery at 6 months. Plast Reconstr Surg. 2007; 119:2192-2199. [PubMed: 17519721]

12. Kau CH, Richmond S, Savio C, Mallorie C. Measuring adult facial morphology in three dimensions. Angle Orthod. 2006; 76:773-778. [PubMed: 17029509]

13. Lines PA, Steinhauser EW. Diagnosis and treatment planning in surgical orthodontic therapy. Am J Orthod. 1974; 66:378-397. [PubMed: 4608690]

14. Maal TJ, Plooij JM, Rangel FA, Mollemans W, Schutyser FA, Berge SJ. The accuracy of matching three-dimensional photographs with skin surfaces derived from cone-beam computed tomography. Int J Oral Maxillofac Surg. 2008; 37:641-646. [PubMed: 18539435]

15. Mah, JHJ.; Bumann, A. The cone-beam decision in orthodontics. McNamara Jr JA, Kapila SD Digital radiography and three-dimensional imaging, 32nd Annual Moyers Symposium; Ann Arbor. 2006. p. 17\{AQ3\}

16. Melsen B. The cranial base. Acta Odontol Scand. 1974:32.

17. Nishii YNK, Takane Y, et al. Integration of the maxillofacial three-dimensional CT image and the threedimensional dental surface image. J Japan Orthod Soc. 1998; 57:189-194.

18. Quast DC, Biggerstaff RH, Haley JV. The short-term and long-term soft-tissue profile changes accompanying mandibular advancement surgery. Am J Orthod. 1983; 84:29-36. [PubMed: 6575615]

19. Sawyer AR, See M, Nduka C. 3D stereophotogrammetry quantitative lip analysis. Aesthetic Plast Surg. 2009; 33:497-504. [PubMed: 18584237]

20. Simmons KE, Turvey TA, Phillips C, Proffit WR. Surgical-orthodontic correction of mandibular deficiency: five-year follow-up. Int J Adult Orthodon Orthognath Surg. 1992; 7:67-79. [PubMed: 1431430] 
21. Terai H, Shimahara M, Sakinaka Y, Tajima S. Accuracy of integration of dental casts in threedimensional models. J Oral Maxillofac Surg. 1999; 57:662-665. discussion 666. [PubMed: 10368089]

22. Thuer U, Ingervall B, Vuillemin T. Stability and effect on the soft tissue profile of mandibular advancement with sagittal split osteotomy and rigid internal fixation. Int J Adult Orthodon Orthognath Surg. 1994; 9:175-185. [PubMed: 7814922]

23. Veltkamp T, Buschang PH, English JD, Bates J, Schow SR. Predicting lower lip and chin response to mandibular advancement and genioplasty. Am J Orthod Dentofacial Orthop. 2002; 122:627634. [PubMed: 12490874]

24. Weinberg SM, Naidoo S, Govier DP, Martin RA, Kane AA, Marazita ML. Anthropometric precision and accuracy of digital three-dimensional photogrammetry: comparing the Genex and 3dMD imaging systems with one another and with direct anthropometry. J Craniofac Surg. 2006; 17:477-483. [PubMed: 16770184]

25. The Academy of Prosthodontics. Glossary of prosthodontic terms. J Prosthet Dent (7th ed). 1999; 81(1):39-110. [PubMed: 10200082]

26. Yushkevich PA, Piven J, Hazlett HC, Smith RG, Ho S, Gee JC, Gerig G. User-guided 3D active contour segmentation of anatomical structures: significantly improved efficiency and reliability. Neuroimage. 2006; 31:1116-1128. [PubMed: 16545965] 

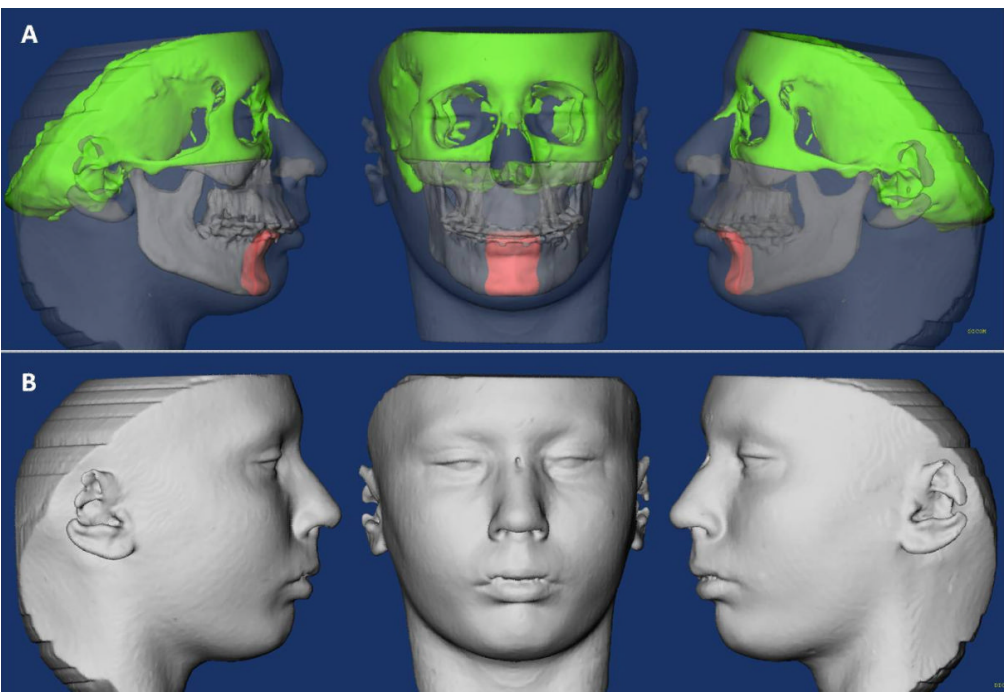

Figure 1.

(A) Image of the segmented hard tissues of interest. (B) Image of segmented soft tissue. 


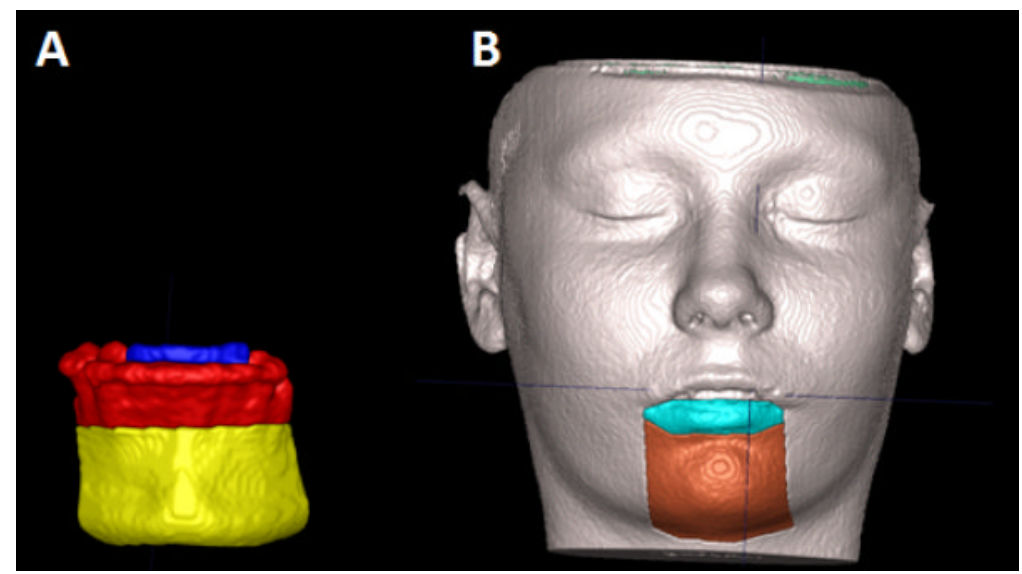

Figure 2.

Demonstration of the areas measured. (A) Blue is where the lower incisors were measured and yellow where the hard chin was measured. (B) Green is where the lower lip was measured and brown where the soft chin was measured. 


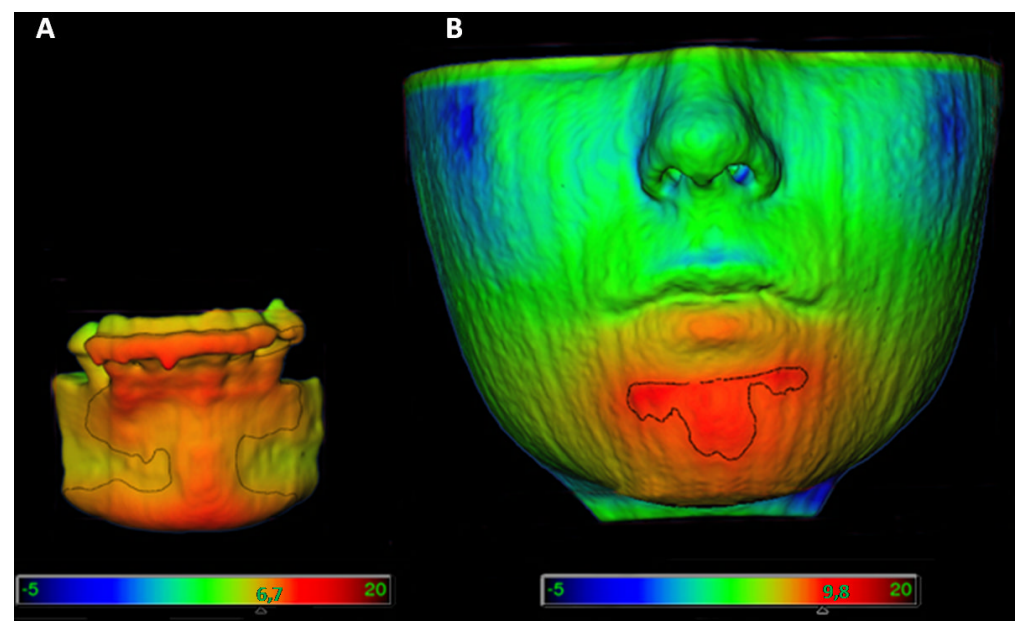

Figure 3.

Illustrations of isolines as a measurement tool on a superimposition of pre- and post-surgery segmentations. (A) Representation of the hard chin and the lower incisors. (B) Representation of the soft chin and the lower lip. The qualitative changes were visualized with color maps that indicate inward (blue) or outward (red) displacement between overlaid structures. An absence of change is indicated by green. ${ }^{20}$ 


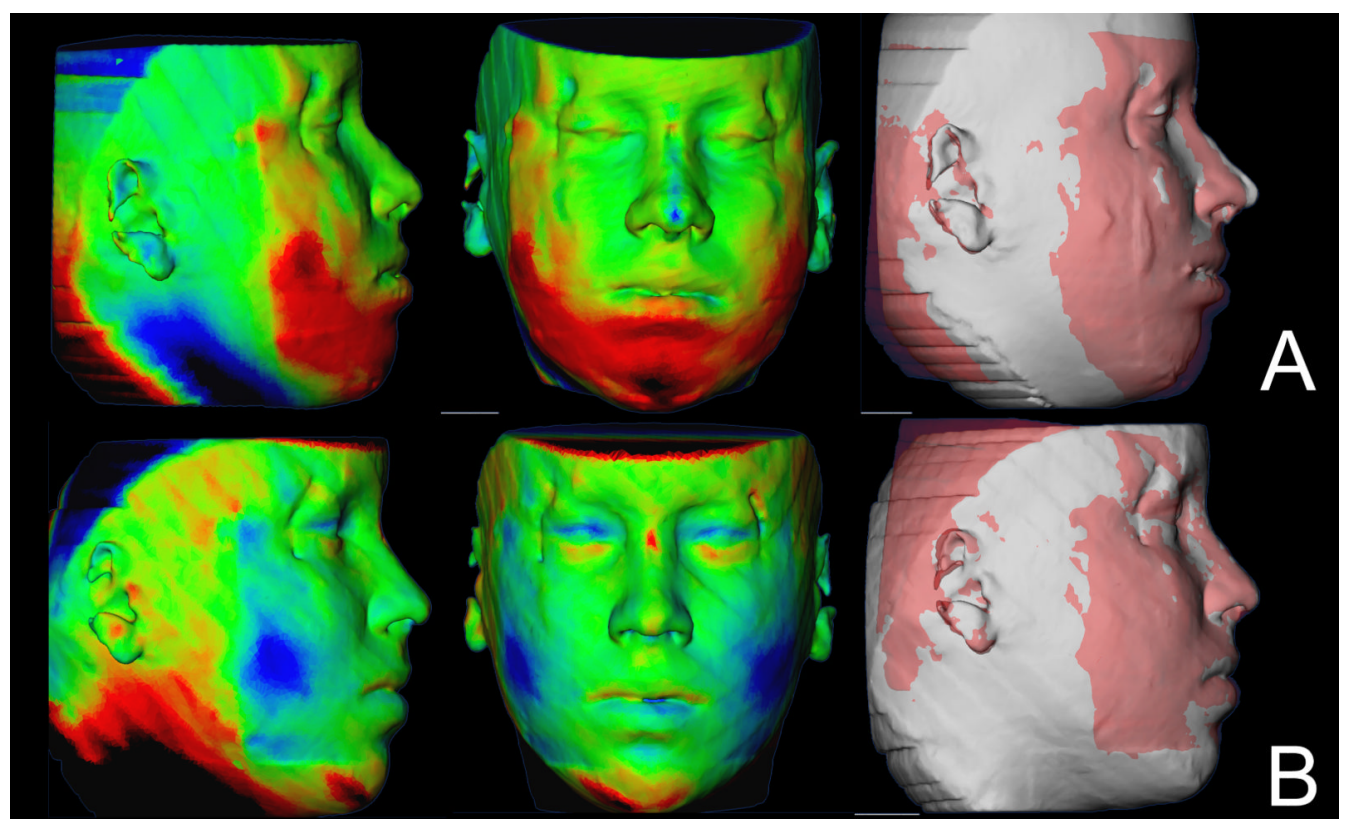

Figure 4.

Example of a case showing improvement of the surgery outcomes 1 year after surgery. (A) Color maps and semi-transparencies of presurgery and splint removal superimposition. (B) Color maps and semi-transparencies of postsurgery and 1 year postsurgery superimposition. Red indicates outward displacement, green no displacement and blue inward displacement. 


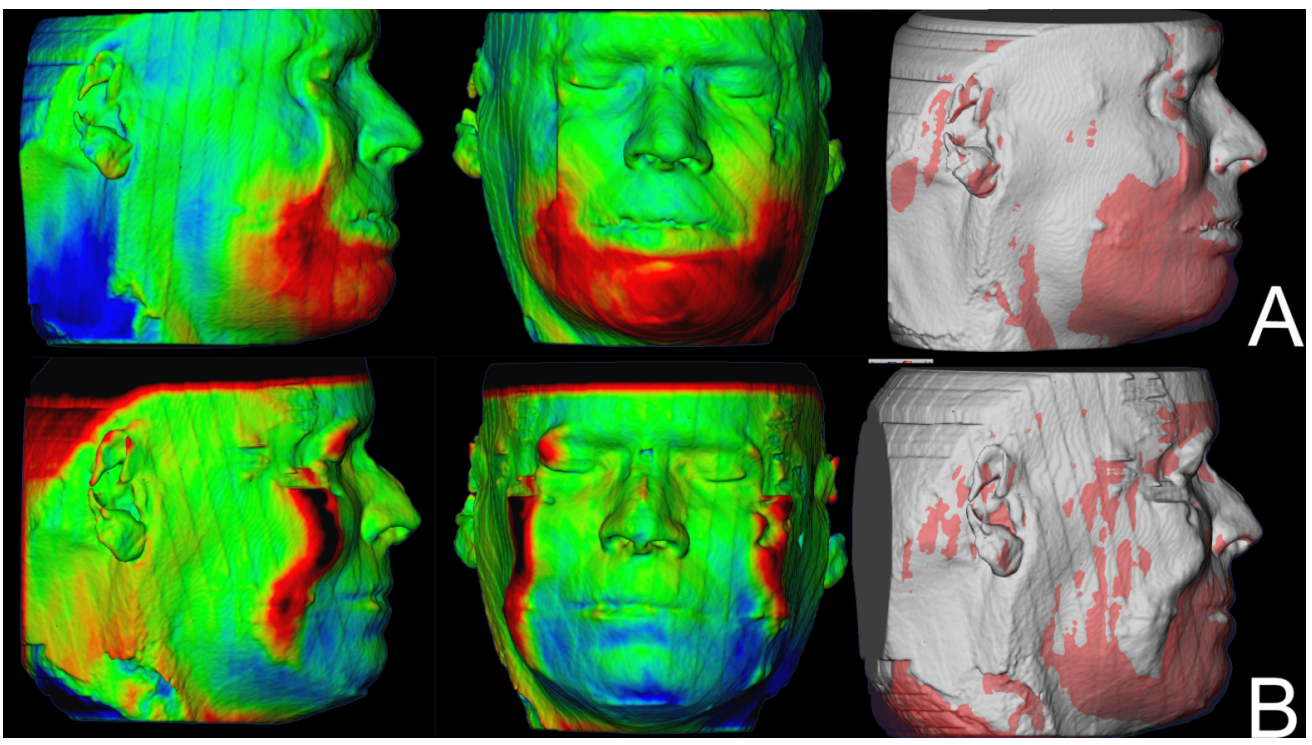

Figure 5.

Example of a case showing relapse of surgery outcomes 1 year after surgery. (A) Color maps and semi-transparencies of presurgery and splint removal superimposition. The noise in the perifery of the CBCT generates artifacts in the soft tissue surface model in this patient. (B) Color maps and semi-transparencies of postsurgery and 1 year postsurgery superimposition. Red indicates outward displacement, green no displacement and blue inward displacement. 


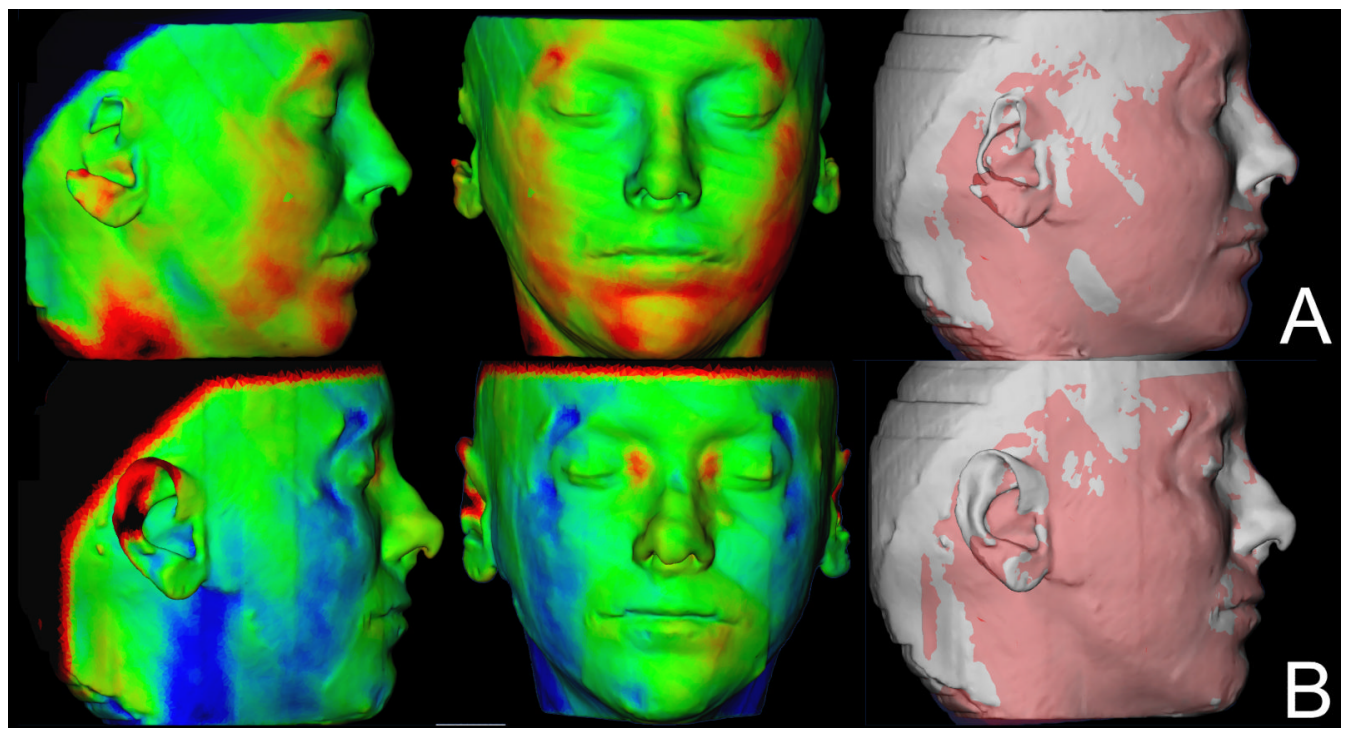

Figure 6.

Example of a case that maintained the surgery outcomes 1 year after surgery. (A) Color maps and semi-transparencies of presurgery and postsurgery superimposition. (B) Color maps and semi-transparencies of postsurgery and 1 year postsurgery superimposition. Red indicates outward displacement, green no displacement and blue inward displacement. 


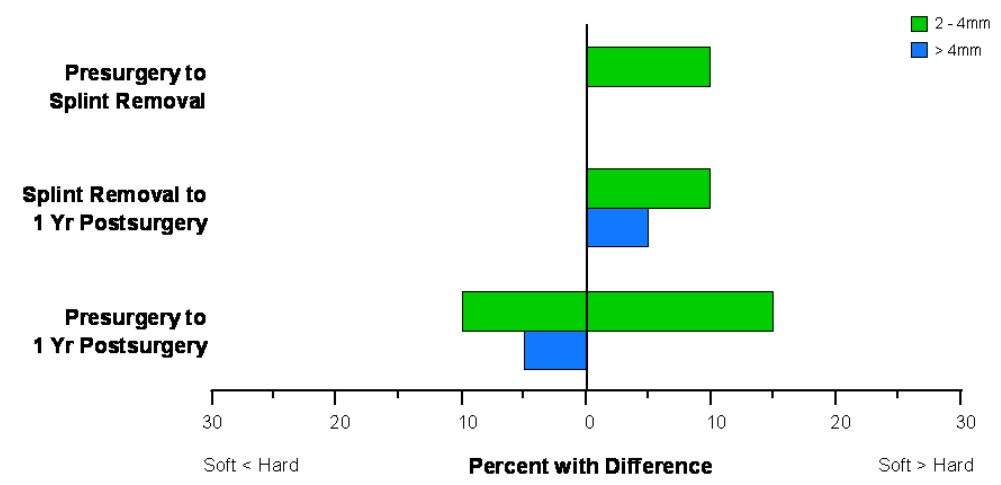

Figure 7.

Percentage of patients with differences in displacements of the hard and soft tissue chin greater than $2 \mathrm{~mm}$. 


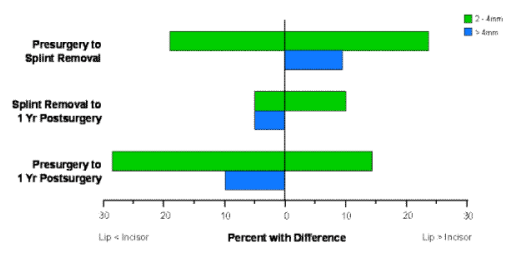

Figure 8.

Percentage of patients with differences in displacements of the lower incisor and lower lip greater than $2 \mathrm{~mm}$. 


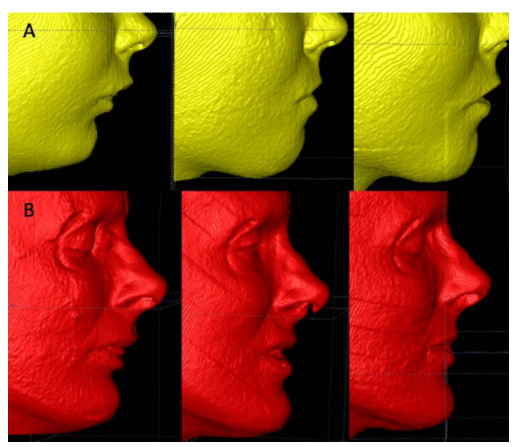

Figure 9.

Example of the three different periods analyzed. Left: images are presurgery. Center: images at splint removal. Right: images at 1 year postsurgery. (A) Patient who had some relapse of the surgery outcomes at 1 year postsurgery. (B) Patients with stable soft tissue results at 1 year postsurgery. 


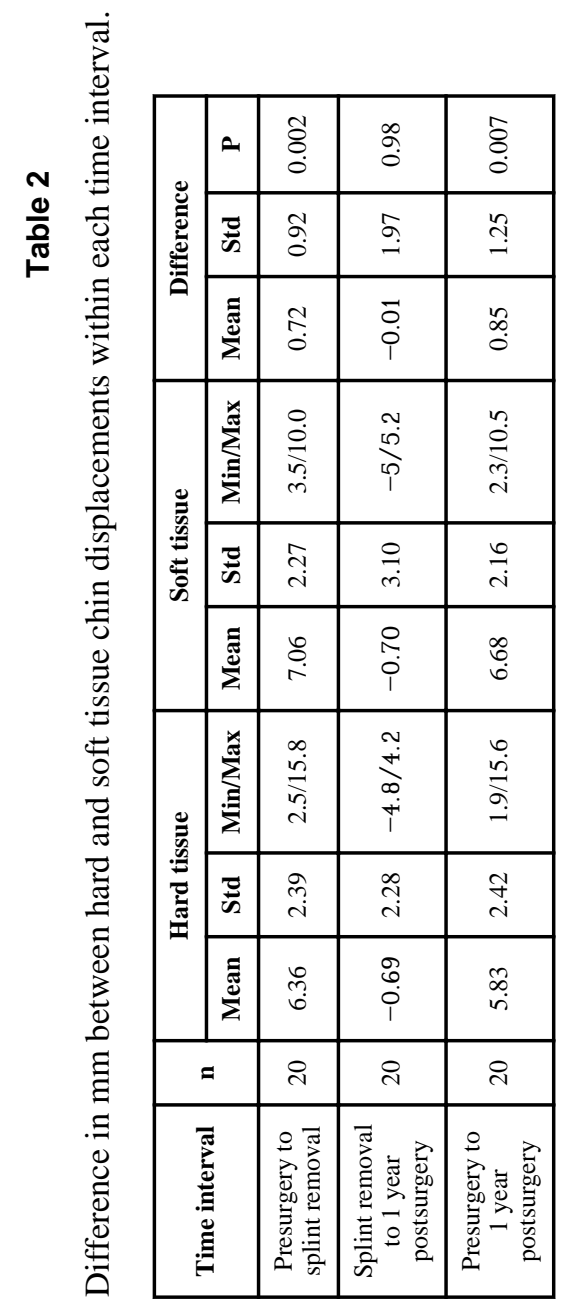

Int J Oral Maxillofac Surg. Author manuscript; available in PMC 2012 April 1. 


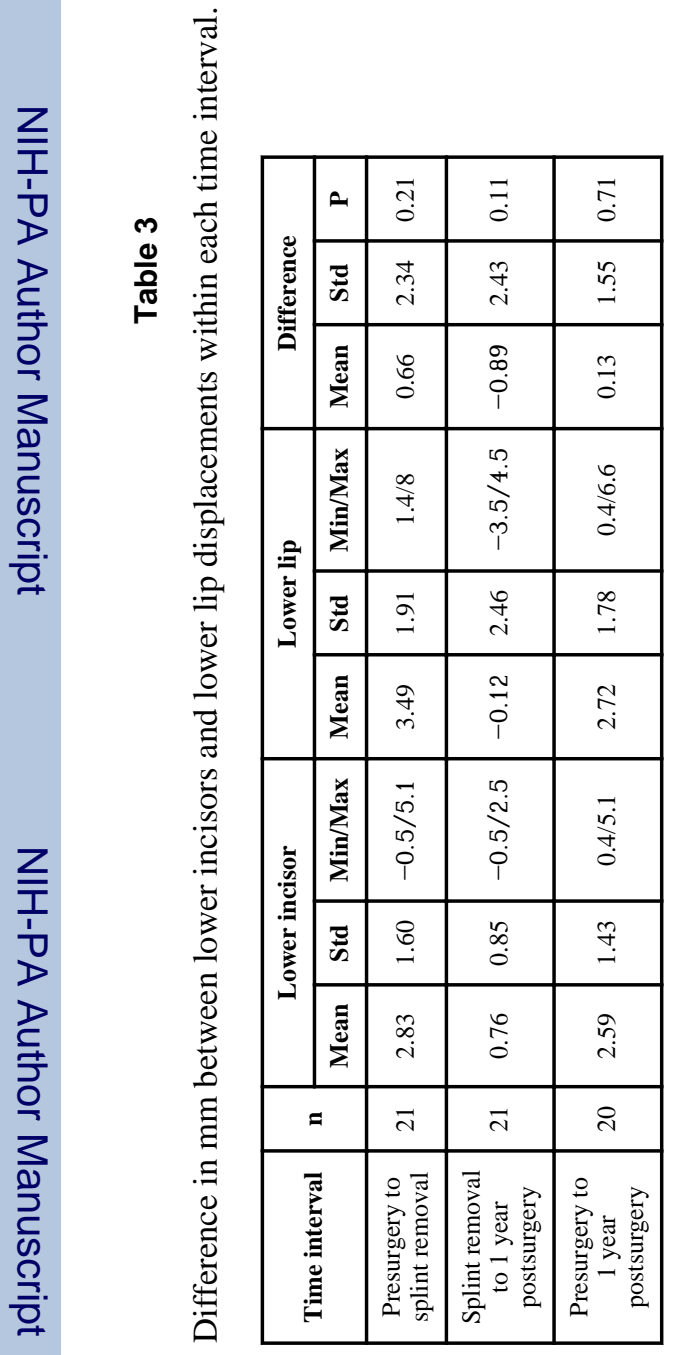

Int J Oral Maxillofac Surg. Author manuscript; available in PMC 2012 April 1. 